RECEBIDO EM 12/08/2013. ACEITO EM 01/12/2015.

\title{
Comportamento estratégico em matéria de gestão de TI: estudo de caso no setor atacadista de alimentos
}

\author{
Cirilo Lemos da Silva \\ Universidade Federal Rural de Pernambuco - UFRPE \\ cirilols@yahoo.com.br
}

\author{
Rodolfo Araújo de Moraes Filho \\ Universidade Federal Rural de Pernambuco - UFRPE \\ rodolfoamfilho@yahoo.com.br
}

\section{RESUMO}

Este trabalho investigou em que medidas as empresas do setor atacadista de alimentos estão utilizando as tecnologias de informação como fator estratégico. A pesquisa foi empreendida no Nordeste, no agreste pernambucano, região onde vem se registrando elevadas taxas de crescimento econômico nas últimas décadas. O estudo teve um cunho exploratório-descritivo e utilizou-se de questionário para a coleta de dados. Os dados foram colhidos de uma amostra de 18 empresas. Foi aplicada uma análise fatorial como técnica estatística de análise de dados. Os resultados sugerem que as empresas do setor demonstram pouca aderência formal ao pensamento estratégico, mas que têm ciência da importância da gerência de TI nos negócios da firma, o que acaba imprimindo um comportamento comprometido com o uso eficiente de TI. Verificou-se que os recursos sustentadores do alinhamento entre negócio e TI são, além da tecnologia adotada, as pessoas, os sistemas de informação e uma melhor infraestrutura organizacional.

Palavras-Chave: Estratégia, Alinhamento Estratégico, Sistemas de Informação, Tecnologia da Informação (TI).

\begin{abstract}
This study investigated to what extent the companies in the wholesale food industry are using information technology as a strategic factor. The research was performed in the Northeast, in the Agreste of Pernambuco, region where high rates of economic growth has been recorded in the recent decades. The study was exploratory-descriptive and used a questionnaire to data collection. The data were collected from a sample of 18 companies. A factorial analysis was applied as the statistical data analysis. The results suggest that the companies show little formal adherence to strategic thinking, but being aware of the importance of IT in business management, which ultimately prints a committed behavior to the efficient IT use. It was found that the supportive resources of alignment between
\end{abstract}


business and IT are beyond the adopted technology, people, information systems and improved organizational infrastructure.

Keywords: Strategy, Strategic Alignment, Information Systems, Information Technology (IT).

\section{Introdução}

No atual estágio de desenvolvimento tecnológico e científico contemporâneo, as instituições tornam-se cada vez mais dependentes das tecnologias de informação e comunicação (TICs). Procedimentos como o envio de uma simples mensagem de texto entre aparelhos de telefonia móvel, ou ainda a realização de transações bancárias utilizando-se desses mesmos aparelhos, eram coisas talvez inimagináveis há algumas décadas.

E essa ubiquidade tecnológica mudou nossa forma de agir diante do mundo: se antes, para a comunicação utilizavam-se documentos escritos como as cartas, que levavam pelo menos alguns dias para chegar aos seus destinatários, hoje utilizam-se os computadores para a troca de mensagens eletrônicas (e-mails) e a mensagem chega ao destinatário em alguns instantes.

Se antes se precisava ir até uma agência bancária para realizar toda e qualquer operação financeira, hoje se pode realizar grande parte dessas transações em postos de autoatendimento bancário, ou via computadores ligados à Internet, ou ainda via aparelhos de telefonia móvel, conforme já citamos.

No que tange ao uso dessas tecnologias no ambiente empresarial, é razoável admitir que, atualmente, nenhuma organização deve conceber sua existência sem o uso de algum tipo de tecnologia de informação. A esse respeito, Albertin e Albertin afirmam que "a oferta de TI e seu aproveitamento amplo e intenso pelas organizações têm sido considerados como uma realidade nos vários setores da economia e condição básica para as empresas sobreviverem e competirem" (ALBERTIN; ALBERTIN, 2005, p. XVIII).

Assim, é cada vez menos provável que alguma organização alcance sucesso sem o uso de modernas tecnologias da informação e comunicação (TICs).

As possibilidades de uso dessas tecnologias pelas empresas são enormes: por exemplo, o processamento de transações tradicionalmente simples e vitais para as empresas, como o registro de pedidos de compras, ou o registro de pagamentos e recebimentos financeiros.

Outra possibilidade de uso das TICs, dentro das empresas, é a facilitação dos processos informacionais como o envio e recebimento de mensagens eletrônicas entre os colaboradores de uma mesma organização com seus clientes e fornecedores, ou entre unidades da mesma organização espalhadas pelo mundo.

Uma forma de utilização mais avançada e atualmente cada vez mais buscada pelas empresas é a geração de informações para montagem de suas estratégias de negócios. Para encontrar essas informações, as empresas precisam processar grandes quantidades de dados de vendas para estimar padrões de consumo e projetar vendas e, consequentemente, o planejamento de compras e a produção, por exemplo.

No entanto, apesar das possibilidades de utilização de computadores e sistemas de informação para as organizações serem inumeráveis, o seu uso nem sempre é fácil. Além disso, embora a consecução do desempenho superior em função da utilização dessas tecnologias seja uma proposta considerada natural, isso nem sempre se estabelece. Essa condição foi identificada através do Paradoxo da Produtividade, que procura explicar o porquê do não aumento da produtividade, apesar dos crescentes investimentos em tecnologias de informação (SOLOW, 1987; ROACH, 1988; BRYNJOLFSSON, 1993; MARTINS, 1996; WAINER, 2003).

O desempenho organizacional pode ser fortemente afetado tanto por fatores externos, quanto por fatores internos às organizações. Como fatores externos, podem-se citar as questões micro e macroeconômicas, políticas governamentais, e a legislação, por exemplo. Por sua vez, alguns dos fatores internos estão relacionados à adoção e utilização de tecnologias pelas organizações, como a adequação tecnológica às necessidades operacionais, a obsolescência, a dificuldade na obtenção de mão de obra especializada, etc. 
Assim, embora a TI possa ser um objeto de vantagem competitiva empresarial, isso pode não ser totalmente conseguido, se se pensar que a TI pode ser vista como uma commodity dentro do processo produtivo de uma organização, ou seja, é algo que é comum a qualquer tipo de organização, se pensada apenas como a aquisição de hardware e software. Nesse sentido, Porter e Millar (1999, p. 84) chamam a atenção para o fato de que "[...] os gerentes precisam compreender, [...], que a tecnologia da informação é mais do que apenas computadores".

Dessa forma, o que faria das TICs um fator de vantagem competitiva é a forma como as mesmas se adequam às estratégias empresariais apoiando os seus processos e aumentando a eficiência e eficácia dos mesmos (HENDERSON; VENKATRAMAN, 1999; LUFTMAN, 2000).

Outra questão bastante discutida no âmbito acadêmico refere-se à possibilidade de mensuração dos benefícios advindos da utilização da TI. Isso acontece porque, embora se tenha como verdade que o uso da TI pode trazer vários benefícios para a organização, como a melhoria no seu desempenho através da promoção do aumento da eficiência e da eficácia operacionais, além das várias possibilidades de redução de custos que a TI pode propiciar ao permitir a automatização de processos, essa mensuração é bastante difícil (SOLOW, 1987; ROACH, 1988; SANTOS; CHAMON, 2008).

Ainda com relação à mensuração de benefícios, a automação de processos está presente, também, na utilização da TI. Essa característica, de uma forma geral, foi muito combatida pelo pensamento de alguns filósofos e sociólogos, de que a utilização da máquina, personalizando a tecnologia, impactaria na diminuição da oferta de emprego em processos produtivos intensivos no uso de mão-de-obra.

A esse respeito, Pinto (2005, p. 133) discorrendo sobre as contradições geradas pelo uso da tecnologia na manutenção das contradições sociais e econômicas entre os países desenvolvidos e subdesenvolvidos, afirma que "com a automação resolve-se um problema real, aumenta-se a produtividade e dispensa-se quase totalmente a mão-de-obra".

Esse tema esteve muito presente nos processos de reengenharia e downsizing que surgiram na última década do século XX, impulsionadas, em parte, pelas possibilidades advindas do aumento no poder de processamento e da automatização de processos propiciadas pelas TICs já disponíveis naquela época. Grandes empresas diminuíram as suas estruturas hierárquicas através do "enxugamento" de seus quadros funcionais (BALLESTERO-ALVAREZ, 2010).

Embora o uso de TI esteja presente em empresas dos três setores clássicos estudados pela economia, ela vem tomando destaque especial, nos últimos anos, em função, principalmente, do uso da Internet para a realização de transações comerciais, o que se convencionou chamar de e-commerce, que pode dar-se entre empresas (B2B), ou entre empresas e consumidores (B2C) (O'BRIEN, 2004; LAUDON; LAUDON, 2004; TURBAN; RAINER; POTTER, 2005).

De acordo com a e-Bit, empresa especializada em coleta de dados sobre vendas eletrônicas no Brasil, o comércio eletrônico brasileiro movimentou em 2011 aproximadamente R \$ 18,7 bi, o que representou um aumento de $26 \%$ em relação a 2010, que foi de $\mathrm{R} \$ 14,8$ bi (E-BIT, 2012).

Além disso, as rápidas transformações que o comércio vem sofrendo com a adoção dos serviços de TI, fez com que este setor se tornasse um dos mais afetados pelas mudanças nos padrões de competitividade e comportamento dos consumidores, dada a velocidade com que cresce a concorrência imputada pelas grandes empresas do varejo on-line, que usam a Internet como plataforma de comunicação para alcançar seus clientes, onde quer que eles estejam.

Todas essas questões aplicam-se, também, ao agronegócio como um todo, a despeito de muitas de suas peculiaridades. De fato, Silva e Batalha (2010) destacam a importância crescente do agronegócio brasileiro para a economia do país.

Dentro da cadeia produtiva do agronegócio, um elo importante que vem buscando melhorar sua competitividade é o setor de distribuição, importante elo das cadeias produtivas de qualquer indústria. Nesse processo, "um fato relevante é a adoção de sistemas logísticos e tecnologias de informação que pode ser vista como um incentivo para a mudança organizacional baseada em novas formas de gestão de cadeias de suprimentos, [...]" (SILVA; BATALHA, 2010, p. 156).

Dada a importância dos canais de distribuição hoje para as empresas, dentre algumas tendências que vêm se desenvolvendo no cenário competitivo atual, a redução de custos é uma temática sempre presente nas estratégias empresariais. Nesse sentido, os custos de distribuição são especialmente importantes, pois, em alguns casos, eles chegam a ser maiores que os custos de 
fabricação, ou maiores que os custos de matérias-primas e componentes (SILVA; BATALHA, 2010, p. 157).

No que tange ao uso das tecnologias de informação para aumentar a eficiência das empresas, visualizando toda a cadeia produtiva, buscando-se a redução dos custos, mas não somente isso, Silva e Batalha (2010, p. 176) afirmam que:

os computadores tiveram sua aplicação inicial como ferramenta de racionalização do trabalho administrativo, mas rapidamente percebeuse que existiam outras formas de se reduzir custos. Uma delas é a possibilidade de reduzir custos de operação a partir do rápido acesso que a tecnologia oferece em termos de informações precisas, em termos de níveis de estoques, rotação e disponibilidades. Nos dias atuais, com utilização da tecnologia de informação para o comércio eletrônico, business-to-business e business-to-consumer, abre-se uma nova forma de se fazer negócios ao longo da cadeia produtiva, chegando até o consumidor final.

Alcançar a máxima eficiência dentro da cadeia de valor de uma indústria é um objetivo que perpassa hoje, todos os elos da cadeia. O setor atacadista, como elo potencializador de demanda, uma vez que está mais próximo dos mercados consumidores, tem fundamental importância para toda a cadeia. Incrementos de produtividade e eficiência no mesmo podem gerar valor para os elos à montante e a jusante do setor.

Percebendo a importância do setor atacadista de alimentos dentro do agronegócio brasileiro, este estudo pretende identificar como se tem dado a adoção e utilização da TI pelas empresas do setor terciário da economia envolvendo especificamente as empresas ligadas ao comércio atacadista de alimentos. O local escolhido para as análises, a cidade de Caruaru no Agreste de PE. A cidade detém hoje, segundo dados do Instituto Brasileiro de Geografia e Estatística (IBGE), o sétimo maior PIB do Estado de Pernambuco, cuja economia vem crescendo a taxas superiores às do país (IBGE, 2010).

Incrementos de produtividade e eficiência em um ramo atacadista como elo potencializador de demanda, podem gerar valor para os elos à montante e a jusante do setor, o que é importante para a economia da região.

Nesse sentido, ao estudar a influência das tecnologias de informação como fator de apoio às estratégias empresariais busca-se compreender os modelos utilizados na gestão de TI pelas empresas em estudo e identificar possíveis oportunidades de utilização mais eficiente dessas tecnologias no setor.

No contexto aqui descrito, tomando-se como premissa que as tecnologias de informação estão presentes em praticamente todas as empresas atualmente, buscou-se responder à seguinte questão de pesquisa: como os sistemas e as tecnologias de informação (SI/TI) têm sido utilizados pelas empresas do setor atacadista de alimentos da região em estudo quanto ao desenvolvimento de suas estratégias empresariais?

Para assim proceder, buscou-se analisar o grau de alinhamento entre os sistemas de informação adotados, com as estratégias das empresas do setor em análise: setor atacadista de alimentos na cidade de Caruaru - PE.

Para tanto, buscou-se, além de traçar o perfil dos gestores e das empresas do setor e de sua gestão, dar respostas aos seguintes objetivos específicos: a) identificar a existência (ou não) do uso de pensamento estratégico na gestão dessas empresas; b) analisar a percepção dos gestores sobre o uso da TI em suas administrações; e, por fim, c) avaliar o nível de alinhamento do uso de TI com as estratégias empresariais dessas empresas.

Dessa forma, com base nos objetivos norteadores da pesquisa, ressaltam-se algumas contribuições trazidas pela mesma nos âmbitos científico e empresarial, ensejadas pelas discussões sobre estratégia empresarial e o uso das TICs como fator estratégico. Esses resultados podem ser utilizados pelas empresas para refletirem sobre suas práticas de gestão.

O que está descrito nessa pesquisa: 
O presente estudo encontra-se organizado em cinco subpartes das quais essa introdução é a primeira. Seguem-se, o referencial teórico ou quadro conceitual, os procedimentos metodológicos adotados, a análise dos resultados e por último, as considerações finais.

\section{Quadro Conceitual}

Buscar-se-á discutir aqui, as principais teorias que darão suporte às observações empíricas sobre gestão de TI e sua ligação com os conceitos de estratégia, competitividade, sistemas de informação estratégicos e a necessidade de alinhamento entre TI e as estratégias de negócios da firma.

\subsection{Noções de estratégia, posicionamento e competitividade}

Conforme assevera Ghemawat (2012, p.1), "apesar de criteriosas tentativas ao longo de décadas para definir e redefinir estratégia [...], uma série de manifestações continua a surgir, buscando redefinir o termo" (grifos do autor).

Segundo Cavalcanti (2006), o pensamento estratégico empresarial tem como um dos seus clássicos o livro Strategy and Structure, de autoria de Alfred D. Chandler Jr., que foi publicado pelo MIT Press em 1962.

Chandler Jr. (1962) define estratégia como sendo "a determinação de metas básicas a longo prazo e dos objetivos de uma empresa, e a adoção de linhas de ação (...) para alcançar essas metas".

Para Ansoff (1990, p. 93) estratégias são "regras e diretrizes para decisão que orientam o processo de desenvolvimento de uma empresa". Porter (1996, p. 68) entende estratégia, "como a criação de uma posição única e valiosa, envolvendo um conjunto de atividades diferenciadas". Aaker (2012, p. 5) defende que, "quatro dimensões definem uma estratégia: a estratégia de investimento no produto-mercado, a proposição de valor ao cliente, os ativos e competências e as estratégias e programas funcionais".

Por sua vez, Mintzberg, Ahlstrand e Lampel (2010) definem estratégia em função do que classificaram como cinco P's, a saber: estratégias como planos e padrões; estratégias como algo deliberado e emergente; estratégias como posições e perspectivas; estratégia como uma manobra específica para fazer frente a um oponente ou concorrente.

Chandler Jr. (1962) em seu estudo clássico onde analisou quatro casos de empresas multinacionais, chegou à evidência de que a estratégia define a estrutura da empresa.

Os conceitos de estratégia e estrutura encontram-se intrinsecamente interligados, visto ser a partir da estrutura que as empresas atingem seus objetivos. E sendo esses objetivos derivados de uma estratégia global da organização (MCCORMACK; JONHSON; WALKER, 2003; DAVENPORT, 2005).

A adaptação do termo para o campo dos negócios que antes estava associado ao aspecto militar, teria se ampliado a partir da segunda revolução industrial, mas só se consolidaria no século $\mathrm{XX}$ após a segunda guerra mundial. Isso porque a guerra teria aguçado o problema de alocação de recursos escassos por toda a economia, o que teria sido um estímulo essencial ao pensamento estratégico relacionado ao âmbito dos negócios (GHEMAWAT, 2012).

Para Fleury e Fleury (2008, p. 54), no que tange aos debates sobre competitividade das empresas, a abordagem clássica é a "análise da indústria" ou do "posicionamento estratégico", que tem Michael Porter (1996) como seu maior expoente.

Para Porter (1996) a competição num setor é definida por cinco elementos, que ele chamou de forças básicas, e o efeito coletivo dessas forças é o que determina em última instância, as possibilidades de rentabilidade do setor.

Porter (1999, p. 56-63) acrescenta a ideia de que o posicionamento pode emergir de três fontes diversas, a saber: posicionamento baseado na variedade; posicionamento baseado nas necessidades; e, posicionamento baseado no acesso. 
No que tange à vantagem competitiva, Oliveira (2005, p. 145-146) sugere que as fontes de vantagem competitiva de uma empresa podem estar localizadas em três pontos: no seu ambiente de operação; em sua situação geral; e, em sua postura de atuação.

\subsection{Sistemas de Informação Estratégicos}

Para O'Brien (2010, p. 292), as empresas visualizam e utilizam a TI de muitas formas. Basicamente, as empresas podem utilizar os sistemas de informação de forma estratégica, de maneira defensiva ou controlada. No primeiro caso, a TI seria encarada como importante diferenciador competitivo por sua administração, que enfatizaria sua utilização estratégica. Para isso, ela investiria significativamente em tecnologia como apoio ao processo decisório e na melhoria dos processos empresariais.

Os sistemas de informação e as tecnologias de informação vêm promovendo grandes mudanças, também, na cadeia de valores, e isso tem impacto sobre todo o sistema de valores de uma indústria.

O sistema de valor é a integração de todas as cadeias (fornecedores, empresa, comprador, entre outros), tendo como objetivo identificar os principais fluxos de processos dentro de uma organização.

De acordo com Daugherty et al. (2009), a forma mais adequada de medir o desempenho de uma cadeia de valor é adotar uma perspectiva de processos. O que conduz a uma visão mais sistêmica, que aquela colocada apenas nas funções departamentais.

Estudos sobre planejamento em negócios utilizam esse referencial teórico para prospectar soluções (VARGAS et al., 2013) o que envolve até questões ligadas à governança (DOLCI; MAÇADA, 2014) e mesmo à sustentabilidade (GOLD; HAHN; SEURING, 2013).

Dessa forma, além de estar impactando na competitividade do setor, a tecnologia da informação está alterando, inclusive, a perspectiva de satisfação do cliente em relação ao produto.

Nesse sentido, Porter e Millar (1999, p. 88) enfatizam que tudo isso explica "[...] porque a tecnologia da informação adquiriu significado estratégico e é diferente das muitas outras tecnologias utilizadas".

A importância estratégica dos sistemas de informação é ressaltada por Laudon e Laudon (2004) quando afirmam que alguns sistemas tornaram-se críticos para o sucesso das empresas no longo prazo. Esses sistemas são chamados de Sistemas estratégicos de informação. Eles "alteram metas, operações ou relacionamentos com o ambiente das organizações para ajudá-las a conquistar uma vantagem sobre os concorrentes. Eles podem até mesmo mudar o negócio das organizações" (LAUDON; LAUDON, 2004, p. 90). Com efeito, as possibilidades de utilização dos sistemas de informação estratégicos são enormes e podem ser observadas na Figura 1. 


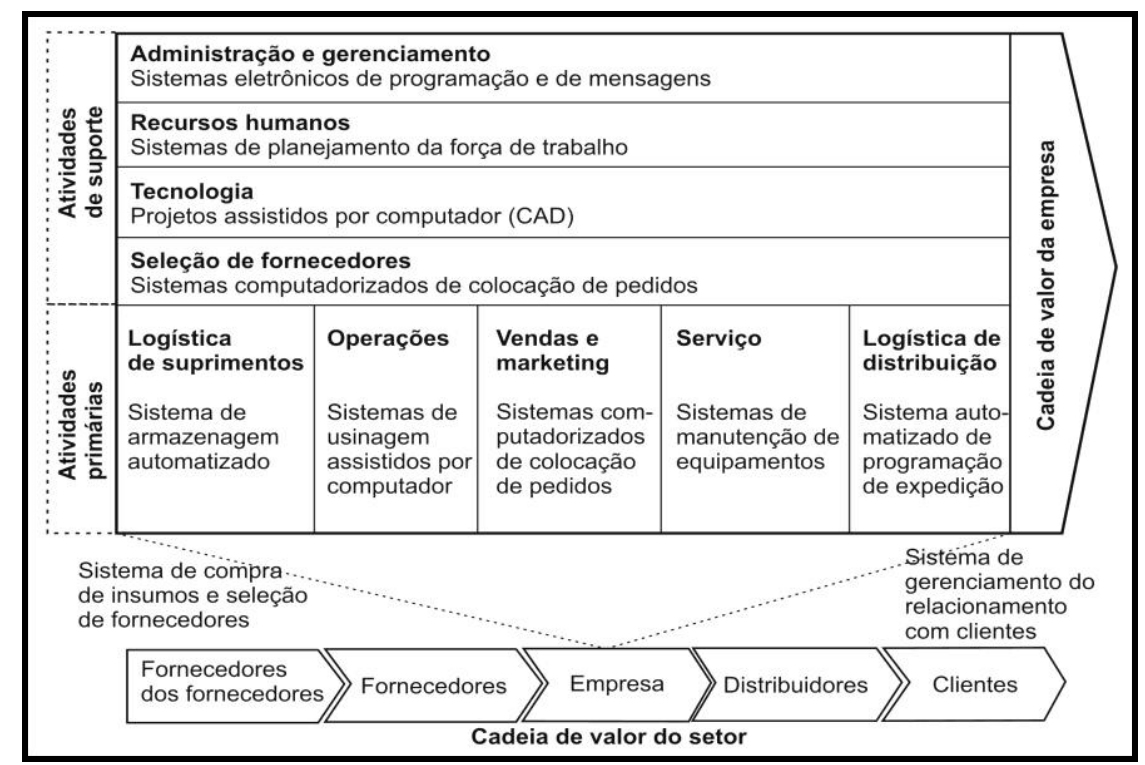

Figura 1 - Sistemas de informação na cadeia de valor da empresa e do setor Fonte: Adaptado de Laudon e Laudon (2004, p. 91).

Esses autores, no entanto, diferenciam os sistemas estratégicos dos sistemas do nível estratégico que são utilizados pelos gerentes sêniores na tomada de decisão e nos problemas de longo alcance. Assim, os sistemas estratégicos podem ser utilizados por todos os níveis organizacionais e sua abrangência é muito maior do que os demais tipos de sistemas utilizados numa organização.

\subsection{O Planejamento Estratégico de TI (PETI)}

As possibilidades de utilização das tecnologias de informação nas organizações e os impactos de uso das mesmas são enormes. Como vimos anteriormente, as tecnologias de informação podem atuar como importante fator de apoio à competitividade empresarial.

No entanto, apesar dos crescentes investimentos em TI, nem sempre as empresas conseguem os retornos esperados em termos de produtividade ou mesmo de vantagem competitiva.

Segundo Santos e Chamon (2008), quando os investimentos em TI parecem não proporcionar os resultados positivos esperados, surge uma aparente contradição. Contradição esta que teria sido batizada pelo economista americano Stephen S. Roach de "Paradoxo da Produtividade" (ROACH, 1988).

Esses problemas podem estar relacionados à falta de alinhamento entre as estratégias organizacionais e as estratégias de TI.

Nesse sentido, Teixeira Filho (2010, p. 22) defende que, "diante da complexidade que a área de SI/TI apresenta e a necessidade constante de melhoria no desempenho dos negócios, o planejamento estratégico de SI/TI está tendo, cada vez mais, um papel decisivo dentro das organizações".

Para Turban, Rainer e Potter (2005, p. 393), os sistemas de informação são desenvolvidos para apoiar processos empresariais, de forma que, "o planejamento desses sistemas precisa estar alinhado com o planejamento global da organização".

O processo de planejamento dos sistemas de informação, na perspectiva desses mesmos autores, não deve ser iniciado pela tecnologia, mas pelo planejamento estratégico da organização, que analisado juntamente com a arquitetura de TI existente, fornecem os dados para o Plano Estratégico de TI (PETI). 


\subsection{O Alinhamento entre a TI e a Estratégia Empresarial}

Henderson e Venkatraman (1999, p. 472) reconhecem e também defendem que a "incapacidade de criar valor dos investimentos em TI, em parte, é devido à falta de alinhamento entre o negócio e as estratégias de TI das organizações".

Aqui no Brasil, o alinhamento estratégico tem sido alvo de estudos pela academia, que tenta validar a importância do mesmo. De fato, pelo menos dois estudos realizados recentemente tentaram traçar um panorama dos estudos sobre a temática aqui no Brasil. Um dos estudos, conduzido por Fialho, Santos e Löbler (2011), pesquisou o número de trabalhos publicados nos anais de dois grandes eventos acadêmicos nacionais: o EnANPAD (Encontro da ANPAD) e o EnADI (Encontro de Administração da Informação).

No total, esses autores encontraram 56 trabalhos publicados nesses dois eventos no período que vai de 2005 a 2010.

Outro estudo que contém direcionamento similar foi o desenvolvido por Ferreira, Marques et al. (2011). Esse trabalho, no entanto, possui maior aprofundamento em alguns detalhes, como o relacionamento dos principais autores e as referências utilizadas nos artigos pelos mesmos. Esse estudo também utilizou a base de dados dos anais do EnANPAD juntamente com o da Revista de Administração Contemporânea - RAC, que também é mantida pela ANPAD. O horizonte temporal dessa pesquisa foi maior que o da anteriormente descrita e atingiu o período de 2001 a 2009.

Nos tópicos a seguir serão apresentados alguns modelos de alinhamento estratégico de acordo com a literatura.

\subsubsection{O modelo de alinhamento de Henderson e Venkatraman}

De acordo com Silva (2009), o modelo de alinhamento proposto por Henderson e Venkatraman (1999) é um modelo clássico e por isso, é muito citado na literatura. O modelo desenvolvido por Henderson e Venkatraman (1999, p. 472-473) está baseado em duas suposições:

a primeira é que o desempenho econômico está diretamente relacionado à capacidade da administração em criar uma adequação estratégica entre a sua posição de competitividade no mercado e o desenho de uma estrutura administrativa adequada para suportar sua execução. [...] A segunda é que a adequação estratégica é essencialmente dinâmica. As escolhas feitas por uma empresa irão desencadear ações imitativas que exigirão respostas subsequentes.

Em consequência disso, os autores defendem que o mais importante na preparação de organização para criar essa capacidade dinâmica de responder às necessidades estratégicas não está na obtenção das últimas novidades tecnológicas, como uma aplicação especifica de TI. Mas, na capacidade da empresa em explorar as funcionalidades da TI e fazê-la apoiar e moldar a estratégia do negócio.

Para Silva (2009), a principal contribuição desse modelo é a flexibilidade quanto à obrigatoriedade de construção das estratégias de negócio antes das estratégias de TI, uma vez que existe uma forte correlação entre ambos e a estratégia de TI pode forçar uma reorientação das estratégias de negócio.

Albertin e Albertin (2010, p. 20) listam as perspectivas de alinhamento dominantes que são: a execução da estratégia, que impõe escolhas na infraestrutura de TI, a transformação tecnológica necessária, o potencial competitivo que exige competências específicas em TI e o nível de serviço que se pretende implantar (serviços de TI de classe mundial, por exemplo). 
O modelo de alinhamento apresentado por Luftman (2000) é um dos modelos bastante citados nos trabalhos acadêmicos referentes à temática do alinhamento estratégico de TI, sendo o autor mais citado em trabalhos realizados aqui no Brasil, de acordo com a pesquisa realizada por Ferreira et al. (2011).

Silva (2009) sugere que esse modelo de alinhamento avalia o grau de maturidade do alinhamento através de critérios advindos de outros modelos clássicos de alinhamento, mais especificamente o Capability Maturity Model (CMM). Assim, o modelo estabelece cinco níveis possíveis de maturidade do alinhamento estratégico (estágio inicial ou processo ad hoc, processo comprometido, processo estabelecido, processo gerenciado melhorado e processo otimizado) e cada nível é avaliado a partir de um conjunto de 06 critérios que são utilizados para avaliar cada um dos cinco níveis de maturidade, a saber: comunicações, competências, governança, parcerias, escopo e habilidades.

\subsubsection{O modelo de alinhamento de Rezende}

Apesar dos diversos modelos de alinhamento já existentes, Resende (2002) apud Silva (2009) destacou que na prática empresarial, não estavam nitidamente definidos os recursos que apoiavam o alinhamento entre o planejamento estratégico (PEE) e o planejamento da tecnologia da informação (PTI).

Na visão de Rezende e Abreu (2010, p. 222), o alinhamento entre PETI e o Planejamento Estratégico (empresarial ou organizacional) é formado a partir de satisfatórias interações entre as funções das organizações privadas e públicas, e tem como resultado a promoção do "ajuste ou a adequação estratégica das tecnologias disponíveis de toda a organização como uma ferramenta de gestão organizacional". Contempla, ainda, os conceitos de qualidade, produtividade, efetividade, modernidade, perenidade, accountability (responsabilidades) e inteligência organizacional.

Para esses autores, os grandes grupos, fatores, ou construtos que dão sustentação ao alinhamento são: a tecnologia da informação, os sistemas de informação e sistemas de conhecimento, as pessoas ou recursos humanos e o contexto ou infraestrutura organizacional (REZENDE; ABREU, 2010, p. 322-323), conforme ilustrado na Figura 2. A dimensão do PETI contempla as configurações da TI (software, hardware, sistemas de comunicação e recursos de gestão de dados e informação) descreve a estrutura estratégica, tática e operacional das informações organizacionais, os sistemas de informação e sistemas de conhecimento, a infraestrutura necessária e as pessoas envolvidas. 


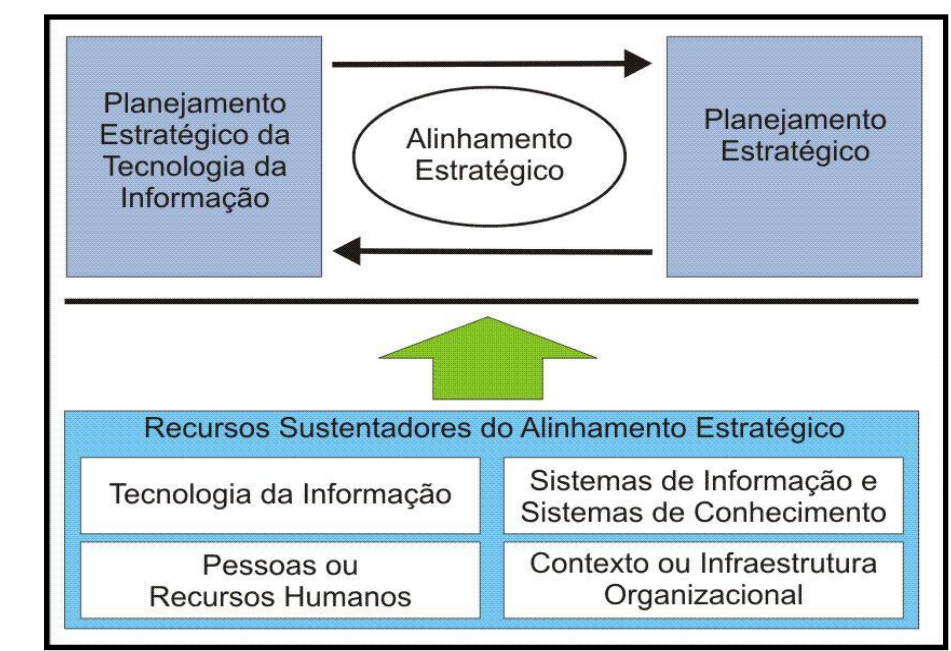

Figura 2 - Modelo de alinhamento estratégico dos planejamentos Fonte: Rezende e Abreu (2010, p. 323).

A dimensão PE fornece os instrumentos necessários para a consecução das estratégias organizacionais, possibilitando uma clara e adequada compreensão das atividades da organização e da atuação de suas funções organizacionais. Contempla, assim, o ambiente interno e externo à organização, com suas ameaças, oportunidades potenciais, favores críticos de sucesso, competências essenciais, etc.

“A dimensão 'recursos sustentadores do alinhamento PETI ao PE' fornece uma visão geral das atividades, variáveis e fatores que facilitam o alinhamento" (REZENDE; ABREU, 2010, p. 324).

\section{Metodologia}

O presente trabalho pode ser classificado quanto à sua finalidade, como sendo uma pesquisa de natureza descritiva e exploratória.

Para Freitas et al. (2000, p. 106) a pesquisa descritiva tem como fito "identificar quais situações, eventos, atitudes ou opiniões, estão manifestos em uma população" sendo esse o objetivo da presente pesquisa: estudar o comportamento das empresas de um setor quanto à gestão de TI.

Para Vergara (2003, p. 66), a pesquisa exploratória “[...] é realizada em área na qual há pouco conhecimento acumulado e sistematizado". Para Marconi e Lakatos (2009), pesquisas exploratórias são investigações de pesquisa empírica cujo objetivo é a formulação de questões ou hipóteses para a realização de uma pesquisa futura mais precisa.

Quanto à abordagem metodológica adotada, uma pesquisa quantitativa, mas também qualitativa (RICHARDSON, 1999).

Roesch (2005, p. 125) afirma que as abordagens quantitativas e qualitativas podem ser utilizadas em qualquer tipo de projeto.

É também um estudo de casos, visto que se isola um setor para se fazer observações empíricas.

\subsection{Universo e Amostra}

O setor de investigação escolhido, o atacadista de alimentos na região agreste de Pernambuco. A delimitação, o município de Caruaru e adjacências, como espaço territorial das empresas pesquisadas.

Conforme dados obtidos no site do MTE, 58 empresas constituíam o universo de empresas do setor atacadista de alimentos em Caruaru (BRASIL. MTE, 2013). 
Utilizou-se uma abordagem de amostra intencional não probabilística que se caracteriza pelo acesso a um número determinado de elementos da população. O critério utilizado para a determinação da amostra foi o de acessibilidade e tipicidade.

No esforço de identificação, conseguiu-se contatar 28 empresas. Dessas 28, cinco receberam o questionário impresso, mas não responderam. Outras cinco não se dispuseram a participar da pesquisa. Teve-se assim, 18 empresas que efetivamente responderam ao questionário das quais 06 classificadas como micro-empresas (até 09 empregados); 04 pequenas empresas (de 10 a 49 empregados); 05 médias empresas (50 a 99 empregados); e 03 grandes empresas (acima de 100 pessoas empregadas) pelo critério do SEBRAE (SEBRAE; DIEESE, 2010).

\subsection{Coleta de Dados}

Além da técnica utilizada de observação direta, a pesquisa utilizou como instrumento para coleta de dados um formulário estruturado com questões fechadas e abertas. Em algumas empresas os questionários foram respondidos com a presença do pesquisador, que preenchia as questões, ao tempo em que conduzia uma entrevista com os gestores daquelas empresas. Em outros casos, o pesquisador apenas acompanhava o gestor para auxiliá-lo na resolução de eventuais dúvidas. Em algumas empresas, ainda, os questionários eram deixados com os gestores e apanhados em data posterior definida pelos mesmos. Nessas empresas, ao se apanhar o questionário, eram efetuadas perguntas no sentido de consolidar percepções quanto à gestão de TI na firma. A pesquisa de campo foi realizada no período de 17 de setembro a 25 de outubro de 2012.

\subsection{Métodos Estatísticos para Análise de Dados}

A análise de dados foi efetuada utilizando-se a estatística descritiva, onde se procurou fazer inferências a partir dos dados coletados. Também foi utilizada uma análise fatorial que compõe os métodos da estatística multivariada utilizando-se a técnica de análise em componentes principais. Os dados foram tabulados e analisados eletronicamente com a ajuda de software especializado (SPSS v.13.0) que foi utilizado também para a construção de tabelas.

A análise fatorial em componentes principais é um método estatístico de natureza quantitativa de redução de dados e tem como fim, agregar variáveis em fatores, permitindo fazer uma síntese do comportamento ou percepção dos integrantes da amostra sobre o fenômeno estudado com o fito de generalizar resultados para toda a população (CORRAR; PAULO; FILHO, 2011), (PESTANA; GAGEIRO, 2005).

Esses métodos auxiliam na seleção dos fatores necessários (em geral em número reduzido) para explicar o comportamento dos indivíduos com respeito ao tema em investigação.

\subsection{Variáveis Pesquisadas}

As variáveis constantes no instrumento de coleta de dados, definidas com base no quadro referencial, procurou cobrir as seguintes dimensões: Caracterização da empresa (perfil da empresa e do entrevistado), existência de planejamento estratégico na firma, percepções sobre o uso das TIC's, alinhamento estratégico de TI e negócio e infraestrutura de TI. Continha o questionário 50 questões formuladas. Parte das questões deveria ser respondida pelo gerente executivo e a outra parte pelos gestores das áreas de TI, por terem a capacitação adequada para prestar os esclarecimentos necessários à consecução da pesquisa. 


\section{Resultados}

$\mathrm{Na}$ busca pela descrição das características da gestão de tecnologias de informação nas empresas pesquisadas, com vista à aferição de seu uso atrelado às estratégias de negócios da firma, foi realizada uma análise fatorial como método estatístico capaz de sintetizar o comportamento das empresas do setor, ressaltando os eixos principais de sua prática gerencial.

\subsection{Identificação dos Eixos Comportamentais na Gestão de TI pela Análise Fatorial}

O primeiro procedimento a se realizar para aplicação de uma análise fatorial é testar se as variáveis consideradas na pesquisa são adequadas ao estudo em pauta. Essa verificação foi realizada mediante uma análise exploratória dos dados.

O número total de variáveis consideradas para cernir o problema havia sido de 50 questões. Essa quantidade, para a análise fatorial, foi reduzida para 20 variáveis retirando-se da lista as de categoria ordinal (onde não se poderia estabelecer uma escala de valor, mas apenas uma ordem) tais como: "tipo de problemas encontrados na gestão dos aplicativos implantados na empresa". Variáveis desse tipo foram exploradas dentro das análises de forma qualitativa a partir das frequências de respostas e das observações diretas.

A partir das variáveis assim selecionadas derivadas do questionário aplicado juntos às empresas, se rodou a AF obtendo-se os resultados apontados na Tabela 1.

Para identificar a qualidade das correlações entre as variáveis de modo a validar a Análise Fatorial (AF), utiliza-se o teste de Kaiser-Meyer-Olkin (Measure of Sampling Adequacy - MSA) e o teste de esfericidade de Bartlett. Caso o MSA indique um grau de explicação menor que 0,50 a AF não pode ser efetuada, visto que os fatores encontrados não descrevem satisfatoriamente as variações dos dados originais. O teste de esfericidade de Bartlett indica, por seu turno, se existe relação suficiente entre as variáveis estudadas para aplicação da AF. Recomenda-se que o teste de significância (valor de Sig) para esse método, não ultrapasse 0,05 .

Tabela 1 - Teste KMO (MSA) e Bartlett's

\begin{tabular}{|l|l|r|}
\hline \multicolumn{2}{|l|}{ Kaiser-Meyer-Olkin (Measure of Sampling Adequacy). } & 0,688 \\
\hline \multirow{3}{*}{$\begin{array}{l}\text { Bartlett's Test of } \\
\text { Sphericity }\end{array}$} & Approx. Chi-Square & 299,149 \\
\cline { 2 - 3 } & $\mathrm{df}$ & 105 \\
\cline { 2 - 3 } & Sig. & 0,000 \\
\hline
\end{tabular}

Fonte: SPSS (dados da pesquisa)

Vê-se na Tabela 1 pelo valor do MSA $(0,688)$ acima de 0,500 que os dados são adequados a uma análise fatorial.

Também o teste de esfericidade de Bartlett com valor obtido de 299,15 e nível de significância (Sig.) menor que 0,01 permite rejeitar a hipótese nula de que as variáveis não sejam correlacionadas. Isso é um reforço ao entendimento de que a AF é adequada ao estudo.

Na sequência dos testes de aderência de aplicação da AF, procedeu-se a análise da matriz de Anti-imagem. No caso em estudo, constataram-se nessa matriz (Anti-image Correlation) em sua diagonal, valores acima de 0,80 o que é mais uma confirmação de que a análise fatorial pode ser aplicada com propriedade ao caso. A regra diz que bastam valores superiores a 0,50 na diagonal da matriz de anti-imagem para atestar a conformidade da $\mathrm{AF}$ em relação às variáveis do estudo.

Procedendo no SPSS uma Análise em Componentes Principais obteve-se como resultado após rotação varimax a extração de 05 fatores explicando cumulativamente $78,967 \%$ da variância total do fenômeno em estudo, qual seja, o comportamento estratégico em matéria de gestão de TI das empresas pesquisadas (Figura 3). 
Isso significa que, saindo de um estado onde se tinha 20 variáveis elas se agregaram agora em 05 fatores, permitindo explicar o fenômeno "Comportamento em matéria de Gestão de TI" em apenas cinco dimensões. O Fator 1 é o mais importante do conjunto explicando $21,62 \%$ da variância.

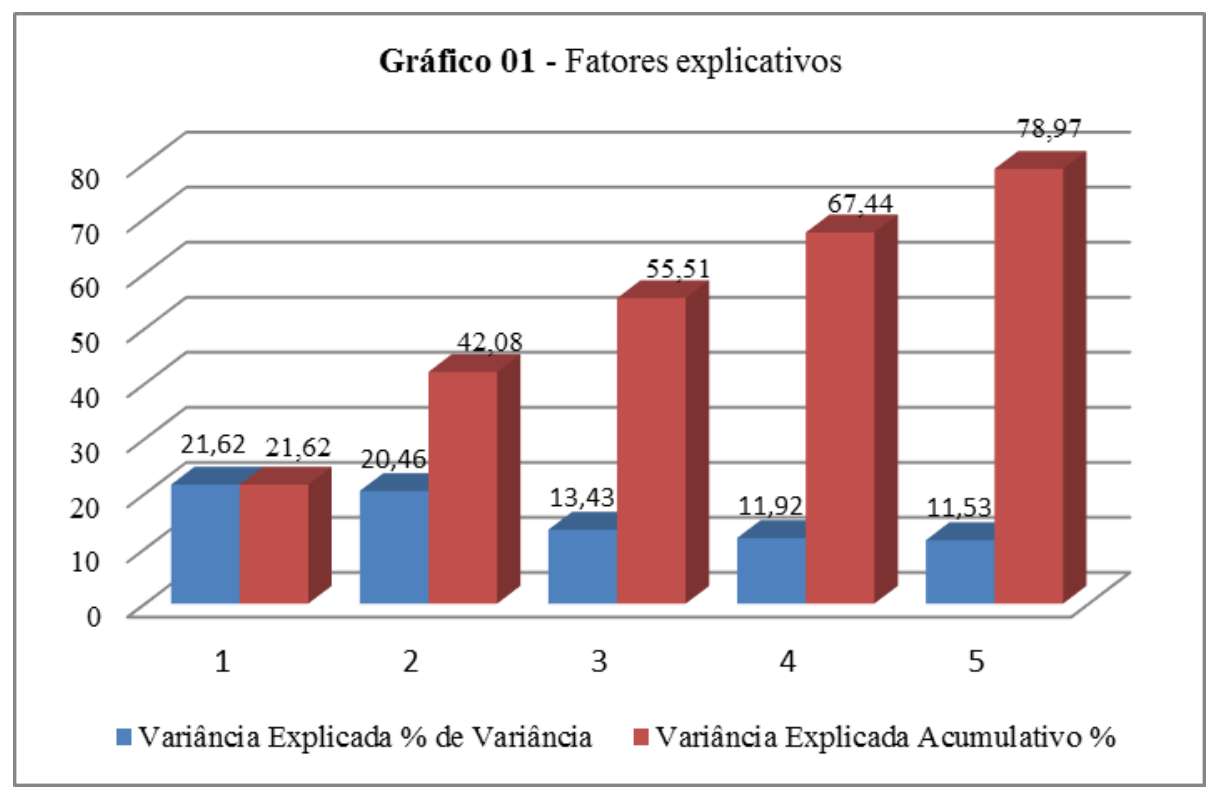

Figura 3 - Gráfico de Fatores explicativos. Fonte: SPSS

Na Tabela 2, como segue, são exibidas as cargas fatoriais das variáveis sobre cada fator, as comunalidades e o percentual de variância total explicada por cada fator de per-si.

As cargas fatoriais superiores a 0,60 encontram-se destacadas na Tabela 2, apontando as variáveis mais fortemente associadas a um determinado fator.

Comunalidade elevada é também uma medida da qualidade da análise fatorial. Em geral acima de 0,70 significa que o método aplicado tem aderência e adequabilidade ao fenômeno que se está estudando. 
Tabela 2 - Extração de Fatores (Análise em Componentes Principais)

\begin{tabular}{|c|c|c|c|c|c|c|}
\hline \multirow{2}{*}{ VARIÁVEIS } & \multicolumn{6}{|c|}{ Componentes Fatoriais } \\
\hline & F1 & $\mathbf{F 2}$ & F3 & F4 & F5 & $\begin{array}{c}\text { Comuna- } \\
\text { lidades }\end{array}$ \\
\hline 1. Escolaridade & 0,279 & 0,786 & $-0,146$ & 0,161 & 0,073 & 0,748 \\
\hline 2. Interesse por TI & $-0,336$ & 0,231 & 0,445 & 0,032 & $\mathbf{0 , 7 2 3}$ & 0,888 \\
\hline 3. Idade da Organização & 0,129 & 0,056 & 0,091 & 0,039 & 0,771 & 0,624 \\
\hline 4. Relevância da TI na Firma & 0,153 & 0,148 & 0,185 & 0,819 & 0,229 & 0,804 \\
\hline 5. Benefícios de TI na Firma (Percepção) & 0,251 & 0,079 & 0,476 & 0,729 & 0,031 & 0,829 \\
\hline 6. Existência de Estratégia Empr. (PEE) & 0,687 & 0,391 & $-0,084$ & $-0,125$ & 0,349 & 0,770 \\
\hline 7. Direção tem conhecimento da estratég. da concorren. & $-0,297$ & $-0,152$ & $-0,101$ & $\mathbf{0 , 8 9 3}$ & $-0,061$ & 0,922 \\
\hline 8. Firma é mais competitiva que a concorrência & 0,089 & $-0,171$ & $-0,023$ & 0,122 & $\mathbf{0 , 8 1 6}$ & 0,719 \\
\hline 9 Gerentes TI Partic. Planej. Estr. da Firma & $\mathbf{0 , 7 8 4}$ & 0,251 & 0,202 & 0,139 & $-0,011$ & 0,738 \\
\hline 10 Formalização Planej. Estr. de TI (PETI) & 0,407 & $\mathbf{0 , 7 2 7}$ & 0,256 & $-0,168$ & $-0,159$ & 0,813 \\
\hline 11. Geren. Exec. participa no Plan. Estr. de TI & 0,671 & 0,529 & 0,110 & 0,008 & $-0,024$ & 0,743 \\
\hline 12. Geren. Exec. e de TI (participa projeto de TI) & 0,659 & 0,596 & 0,071 & $-0,102$ & $-0,105$ & 0,816 \\
\hline 13. Alinham. Estr. TI c/ Estr. da Firma & 0,313 & $\mathbf{0 , 7 6 7}$ & 0,320 & $-0,178$ & $-0,089$ & 0,828 \\
\hline 14. Invest. TI tem valor até s/ poss. medir & 0,447 & 0,320 & 0,586 & 0,335 & 0,198 & 0,797 \\
\hline 15. Téc. TI conhecem a Estratégia Negócio Firma & $\mathbf{0 , 7 3 5}$ & 0,532 & $-0,113$ & $-0,067$ & 0,133 & 0,858 \\
\hline 16. Redução de Custos c/ Medida de Sucesso TI & 0,385 & 0,431 & 0,672 & 0,001 & 0,204 & 0,827 \\
\hline 17. Implantação de Projeto de TI tem tido sucesso & 0,090 & $-0,074$ & $\mathbf{0 , 8 5 6}$ & 0,119 & 0,174 & 0,792 \\
\hline 18. Capac. em TI relacion. / Cresc. da Firma & 0,214 & 0,764 & $-0,084$ & 0,272 & 0,141 & 0,730 \\
\hline 19. TI melhora comunicação e colabora no trabalho & 0,172 & 0,440 & $-0,605$ & $-0,151$ & 0,379 & 0,756 \\
\hline 20. Tamanho ( $\mathrm{N}^{\circ}$ Func. p/ Faixa.) SEBRAE & $\mathbf{0 , 8 5 3}$ & 0,135 & 0,196 & 0,086 & 0,040 & 0,793 \\
\hline Variância explicada por fator e total & 21,62 & 20,46 & 13,43 & 11,92 & 11,53 & $\mathbf{7 8 , 9 6}$ \\
\hline
\end{tabular}

Fonte: SPSS (Dados da Pesquisa)

\subsection{Análise dos Componentes Principais}

Definidos os principais eixos que explicam o comportamento das empresas do setor estudado, quanto à sua postura em matéria de gestão de TI, cabe agora interpretar os fatores.

O Fator1 correlacionado com as variáveis $6,9,11,12,15$ e 20 explicando 21,62\% do comportamento geral relativo à gestão de TI na firma pode ser entendido, pela natureza das variáveis correlacionadas (Tabela 2) como: Alinhamento dos Planejamentos (PEE e PETI).

Com efeito, pode-se depreender do Fator 1 que as empresas procuram praticar em sua gestão, cada qual à sua maneira e à sua intensidade, o planejamento estratégico empresarial (V6 - Existência de PEE).

Os resultados estão dispostos na Tabela 3 a seguir, onde se vê que apenas $16,7 \%$ declararam não ter nenhuma preocupação com o PEE.

Pode-se perceber que mesmo que não haja um percentual elevado de empresas com PEE documentado, a importância de sua existência não é ignorada. Pelo contrário, tem-se na amostra pelo menos $60 \%(50,0+11,1)$ de empresas que declararam a existência e estruturação de algum tipo de PEE na firma. 
Tabela 3 - Existência de uma estratégia empresarial (V6)

\begin{tabular}{l|ccc}
\hline \multicolumn{1}{c|}{ Situação } & Frequência & Percentual & $\begin{array}{c}\text { Percentual } \\
\text { Acumulado }\end{array}$ \\
\hline Não temos uma estratégia de negócio & 3 & 16,7 & 16,7 \\
Existe apenas na mente da Diretoria & 4 & 22,2 & 38,9 \\
É intuitivamente conhecida pela Diretoria & 9 & 50,0 & 88,9 \\
Está oficializada em documento & 2 & 11,1 & 100,0 \\
\hline Total & 18 & 100,0 & \\
\hline
\end{tabular}

Fonte: SPSS (Dados da pesquisa)

As variáveis seguintes V9, V11, V12 e V15 correlacionadas a esse fator, indicam que:

- (V9) - o planejamento estratégico empresarial praticado busca contar com a participação do pessoal de TI (média de 2,83 na escala de Likert);

- (V11) - para a definição das políticas da área de TI tem-se a participação dos gerentes executivos da firma (média de 2,67).

- (V12) - os projetos de TI da empresa são discutidos em conjunto pelos gerentes executivos e o gestor/assessor de informática (média de 2,44); e,

- (V15) - que os técnicos responsáveis pela TI são cientes dos objetivos da organização e de suas estratégias empresariais (média 2,44).

Tem-se por fim, que esse fator (Fator 1) apresenta-se fortemente correlacionado (carga fatorial: 0,853 ) com a variável 20 "Tamanho ou porte da organização" (média 2,28). Isso pode estar a indicar, na prática, ser o esforço de planejamento e seu alinhamento mais intensamente praticado pelas empresas com maior estrutura.

Vê-se nesse último item confirmado o modelo teórico de alinhamento estratégico dos planejamentos (PE e PETI) definido por Rezende e Abreu (2010) onde os recursos sustentadores desse alinhamento são: a TI, as pessoas, os sistemas de informação (SI) e uma melhor infraestrutura organizacional conforme discutido na seção 2.5.3 no esquema da Figura 2.

O Fator 2 correlacionado com as variáveis 1, 10, 13 e 18 (Tabela 2) explicando mais 20,46\% da variância total do fenômeno estudado pode ser interpretado como Preocupação com a Formalização do PETI.

Com efeito, esse fator está relacionado a uma maior escolaridade do quadro gerencial (V1) permitindo fazer destacar no processo de gestão, a preocupação com a necessidade de formalização do Planejamento Estratégico de TI (V10) e o alinhamento com as estratégias de negócios da firma (V13).

Percebe-se ainda nesse fator, a crença na importância da capacitação em TI do quadro de pessoal como condição necessária ao crescimento dos negócios da firma (V18) indicando que os gestores têm a plena consciência de que é preciso investir nas pessoas para que as mesmas façam o uso eficiente do ferramental tecnológico disponível.

Na prática, esse fator representa muito mais uma intensão de atuação das firmas, com respeito à adequação de seus projetos de TI, alinhados com os negócios da empresa, do que propriamente um comportamento padrão. Observou-se nas entrevistas semi-diretivas que muitas empresas, em que pese estarem estruturadas com modernas tecnologias, não possuem uma visão clara do caminho a seguir, para vincular de forma estratégica essa tecnologia aos negócios da firma.

O que pode ser constatado pela existência de muitos sistemas de informação ligados às atividades fins da empresa em sua cadeia de valor, tais como sistema de compras e/ou cadastramento de fornecedores, gestão de estoques e processamento de pedidos, mas proporcionalmente poucas empresas com ações de interligação desses sistemas com os sistemas dos fornecedores ( 05 em um total de 18) como forma de otimizar eventuais pedidos de matérias-primas (Supply Chain Management). Do outro lado da cadeia (à jusante) apenas uma empresa apresentou aplicativo interligado com os clientes.

Ações que poderiam ser fortemente otimizadas por meio de sistemas gerenciais de relacionamento com clientes (ECR - Efficient Consumer Reponse) objetivando aumentar vendas por meio de ações de "sortimento eficiente" e "reposição eficiente" como é destacado na Figura 1 de acordo com Laudon e Laudon (2004, p. 91). 
O Fator 3 relacionado com as variáveis 16, 17 e 19 explicando 13,43\% da variância total, perfazendo 55,52\% do entendimento geral sobre o comportamento das empresas do setor quanto à gestão de sua tecnologia, pela natureza das variáveis correlacionadas (Tabela 2) pode ser denominado de Conformidade dos projetos de TI/SI.

Esse fator revela que as firmas estão satisfeitas com o resultado dos projetos de TI implantados, cuja percepção é a de que estão obtendo sucesso (V17), contribuindo inclusive, segundo sua visão, "para a redução de custos" (V16). Esses resultados revelam que os aplicativos são de cunho mais gerencial e não sistemas colaborativos de melhoria de comunicação entre funcionários internamente (V19). Isso está explicito pela forma como essa variável (V18) vincula-se ao Fator 3, cuja carga é negativa $(-0,605)$.

O Fator 4 correlacionado com as variáveis 4, 5 e 7 explicando 11,92\% da variância total, pela natureza das variáveis coligadas (Tabela 2), pode ser interpretado como Percepção da importância de TI.

Com efeito, esse fator revela o grau de importância que as firmas atribuem a TI (V4) e os benefícios gerados para os negócios (V5), mesmo que não seja fácil se medir em termos financeiros seus aportes.

Também está associado a esse fator, o conhecimento que as empresas entendem possuir das estratégias adotadas pela concorrência (V7), o que vem medir a compreensão e competência das gerências em analisar o ambiente concorrencial.

O Fator 5 (último fator) relacionado com as variáveis 2,3 e 8 , a tirar pelo que as variáveis expressam, pode ser denominado como Fator Maturidade.

Com efeito, esse fator é explicado pela variável V2 "Interesse por TI" e também a variável V3 "Idade da Organização". A intepretação é que quanto maior a experiência da empresa no setor (maior tempo de funcionamento) maior o seu interesse por TI como forma segura de estabelecer vantagem competitiva frente ao seu concorrente.

Como que atestando essa intepretação, agrega-se ainda ao Fator 5 a variável V8, em que a empresa afirma sentir-se "tão ou mais competitiva que as empresas da concorrência".

\subsection{Síntese do Comportamento das Empresas do Setor na Gestão de TI}

O conjunto dos cinco fatores que sintetizam o comportamento das empresas do setor estudado, quanto à gestão de TI, explica 78,96\% da variância total do fenômeno em exame, o que é considerado um percentual elevado. Isso equivale dizer que os fatores extraídos são as dimensões principais (análise em componentes principais) que explicam o comportamento das empresas do setor quanto à gestão de TI. O esquema do Tabela 4 faz a síntese desse comportamento.

Tabela 4 - Síntese do comportamento das empresas quanto à gestão de TI no setor industrial estudado

\begin{tabular}{|c|c|c|}
\hline Componente & Conceituação & $\begin{array}{c}\text { \% de variância } \\
\text { explicada }\end{array}$ \\
\hline Fator 1 & Alinhamento dos Planejamentos (PEE e PETI) & 21,62 \\
\hline Fator 2 & Preocupação com a Formalização do PETI & 20,46 \\
\hline Fator 3 & Conformidade dos Projetos de TI. & 13,43 \\
\hline Fator 4 & Percepção da Importância de TI & 11,92 \\
\hline Fator 5 & Maturidade & 11,53 \\
\hline \multicolumn{2}{|r|}{ Total $\rightarrow$} & $\mathbf{7 8 , 9 6}$ \\
\hline
\end{tabular}

Fonte: SPSS (dados da pesquisa) 
Depreende-se da análise do Tabela 4 a existência de um comportamento médio do conjunto das empresas em estudo com respeito à gestão de TI a partir das dimensões extraídas da análise fatorial (análise em componentes principais).

\section{Considerações Finais}

O objetivo geral que norteou o desenvolvimento do presente trabalho foi o de analisar a utilização das tecnologias de informação (TI) nas estratégias mais gerais das empresas do setor atacadista de alimentos da cidade de Caruaru - PE.

Nesse sentido, para estudar a influência das tecnologias de informação como fator de apoio às estratégias empresariais, buscou-se compreender os modelos utilizados na gestão de TI pelas empresas e identificar possíveis oportunidades de utilização mais eficiente dessas tecnologias no setor.

Para isso, buscou-se analisar o grau de alinhamento da TI com as estratégias empresariais nos negócios da firma.

Utilizou-se para apoiar o estudo, a análise fatorial, técnica estatística de redução de dados que permite agregar informações em fatores ou componentes principais facultando a compreensão da variação do fenômeno a ser explicado.

Procedendo aos estudos, verificou-se que, com respeito ao perfil gerencial médio das empresas, o quadro de dirigentes apresenta boa formação acadêmica, o que é um fator importante para que a TI seja implantada na empresa dentro de uma perspectiva estratégica.

Com efeito, no que tange ao uso de TI pelas empresas, a pesquisa apontou que os gestores caracterizam-se como tendo uma visão estratégica da TI, investindo em tecnologia por a perceberem como fonte geradora de diferencial competitivo.

Fazem uma avaliação bastante positiva sobre o valor dos investimentos em TI, mesmo sem a certeza dos retornos financeiros dos mesmos (o que é sempre difícil, de se aferir) e que de uma forma geral, as empresas tem tido sucesso na implantação de projetos de TI.

De uma forma geral, os gestores demonstram ter uma visão razoavelmente nítida do ambiente competitivo de suas empresas e da competitividade do setor, o que é importante para a gestão dos negócios.

Verificou-se que as empresas do setor em análise, buscam cada uma a seu modo, promover um planejamento mínimo de TI (PETI) e alinhá-lo com as estratégias de negócios da firma (PEE), o que ficou explicito no principal fator extraído da análise em componentes principais (Fator 1 Alinhamento dos Planejamentos).

Indagou-se ainda sobre a compreensão que os gestores têm sobre a importância da capacitação das pessoas na utilização adequada da TI, como fator de grande relevância para o desempenho da empresa. Constatou-se que os gestores têm a consciência de que é preciso investir em treinamento.

Dessa forma, as pessoas irão trabalhar de forma mais eficaz e eficiente, o que fará com que a empresa, como um todo, possa tornar-se mais eficiente e, portanto, mais competitiva.

Buscou-se aqui compreender em que medida as empresas estão utilizando (ou podem utilizar) as possibilidades dos sistemas de informação atualmente disponíveis para criar uma maior integração da cadeia produtiva de alimentos. Isso porque, como o distribuidor/atacadista funciona como elemento de escoação da produção entre o produtor e os mercados consumidores, compreende-se que quanto maior for a integração desse elo da cadeia de valor, e quanto mais eficiente ele puder se tornar, maiores podem ser os ganhos de eficiência de toda a cadeia de valor, favorecendo assim seus elos, à montante e à jusante da cadeia de valor (Figura 1).

Do ponto de vista da integração da cadeia de valor, de uma forma geral, as empresas pesquisadas mostraram-se fracamente integradas, uma vez que apenas $27,8 \%$ das empresas pesquisadas (5 dentre 18 empresas) têm sistemas de informação integrados com seus fornecedores, enquanto que apenas 5,6\% disseram possuir integração com sistemas de informação de clientes.

Como visto, com relação à noção de gerenciamento da cadeia de suprimento, existem algumas empresas que fazem uso desse tipo de sistemas de informação estratégico. 
Na outra ponta (à jusante do sistema) apenas uma empresa dentre as 18 pesquisadas declarou possuir sistemas integrados com os clientes.

Acredita-se que, embora essa solução possa parecer um tanto nova para a realidade local, ela deva ser um dos próximos passos a se dar na região que poderá trazer grande vantagem competitiva para aquelas empresas que conseguirem implantar esse tipo de solução.

Isso porque, como as empresas do setor trabalham com produtos padronizados, sua principal diferenciação concentra-se na qualidade da prestação de serviços e essa inovação poderá trazer uma melhoria significativa nos processos da empresa e, por conseguinte, na qualidade dos serviços prestados aos seus clientes, que são as empresas varejistas.

Como se pode observar, as oportunidades e benefícios advindos desse nível de informatização da cadeia de valor são muitos.

Outras recomendações se situam em nível de promoção de palestras, seminários e/ou cursos de curta e média duração nas associação de classes das empresas do setor, no sentido de se passar o maior número de informações possível aos gerentes responsáveis pela TI nas firmas, com vistas a demonstrar novas oportunidades de melhorias para as empresas que já utilizam, em qualquer grau, tecnologias e sistemas de informação.

Do ponto de vista conceitual, a contribuição da pesquisa foi a de ter confirmado empiricamente o modelo de alinhamento dos planejamentos (PETI e PEE) avançado por Resende e Abreu (2010, p. 324). Verificou-se, conforme ensinam os autores, que os recursos sustentadores desse alinhamento são: as tecnologias de informação, as pessoas, os sistemas de informação (SI) e uma melhor infraestrutura organizacional. O que é compatível com o maior porte da empresa.

De um ponto de vista metodológico, a evidenciação da ideia de que os métodos estatísticos de análise multivariada de dados podem servir de instrumental por excelência para se estudar as estratégias sobre gestão de TI em setores específicos da economia, por seu grande potencial de redução de dados permitindo uma melhor compreensão do fenômeno em investigação.

Numa visão de síntese do estudo efetuado, retomando os objetivos específicos da pesquisa, que foram: identificar a existência (ou não) do uso de pensamento estratégico na gestão das empresas; analisar a percepção dos gestores sobre o uso da TI em suas administrações; e, por fim, avaliar o nível de alinhamento dos sistemas de TI com as estratégias empresariais das empresas pesquisadas, pode-se afirmar que:

No que concerne à gestão estratégica, o exercício do pensamento estratégico parece dar-se de forma ainda incipiente, com poucas empresas admitindo possuir um planejamento estratégico formal. Apesar disso, de uma forma geral, os gestores entendem ter uma visão razoavelmente nítida do ambiente competitivo do setor onde atuam e da competitividade de suas empresas.

Quanto ao capítulo do alinhamento estratégico, de uma forma geral, os dados sugerem que o alinhamento estratégico entre a TI e as estratégias empresariais se dá dentro de uma escalabilidade métrica, de média para baixa, considerando como aferição o intervalo de Likert.

No que tange à percepção de importância do uso da TI pelas empresas, entretanto, a pesquisa mostrou que os gestores fazem uma avaliação bastante positiva sobre o valor dos investimentos em TI, mesmo sem a certeza de retornos financeiros a curto e médio prazo. E que consideram de uma forma geral, que suas empresas têm tido sucesso na implantação de projetos de TI.

\section{Referências}

AAKER, David E. Administração estratégica de mercado. 9. ed. Porto Alegre: Bookman, 2012.

ALBERTIN, Alberto Luiz; ALBERTIN, Rosa M. de Moura. Tecnologia de Informação e

desempenho empresarial: as dimensões de seu uso e sua relação com os benefícios de negócio. São Paulo: Atlas, 2005. 
ALBERTIN, Alberto Luiz; ALBERTIN, Rosa Maria de Moura. Estratégias de governança de tecnologia de informação: estruturas e práticas. Rio de Janeiro: Elsevier, 2010.

ANSOFF, H. Igor. A nova estratégia empresarial. São Paulo: Atlas, 1990.

BALLESTERO-ALVAREZ, Maria Esmeralda. Gestão da qualidade, produção e operações. São Paulo: Atlas, 2010.

BRASIL. MTE. Dardo 10.0.32 - Base de Gestão do MTE:CAGED. Base de Gestão do MTE: :CAGED, 2013. Disponivel em: 〈http://bi.mte.gov.br/bgcaged/>. Acesso em: 13 mar. 2013.

BRYNJOLFSSON, Erik. The Productivity Paradox of Information Technology. Communications of the ACM, New York, v. 36, n. 12, December 1993. p. 67-77.

CAVALCANTI, Marly. A evolução do pensamento estratégico. In: CAVALCANTI, Marly. Gestão estratégica de negócios: evolução, cenários, diagnóstico e ação. São Paulo: Pioneira, 2006.

CHANDLER JR., Alfred D. Strategy and Structure: charters in the history of the industrial enterprise. Massachusetts: MIT Press, 1962.

CORRAR, Luis J.; PAULO, Edilson; FILHO, José Maria Dias. Análise multivariada: para os cursos de administração, ciências contábeis e economia. 1. ed. São Paulo: Atlas, 2011.

DAUGHERTY, Patricia J; CHEN, Haozhe; MATTIODA, Daniel D.; GRAWE, Scott J. Marketing/logistics relationships: influence on capabilities and performance. Journal of Business Logistics, v. 30, n. 1, p. 1-18, 2009.

DAVENPORT, Thomas H. The Coming Commoditization of Processes. Harvard Business Review. v. 83 , n. 6 , p. $100-108,2005$.

DOLCI, Pietro Cunha.; MAÇADA, Antonio Carlos Gastaud. Information Technology Investments and Supply Chain Governance. RAC. Revista de Administração Contemporânea, v. 18, n. 2, p. 217-235, 2014.

E-BIT. WebShoppers. 25. ed. [S.1.]: [s.n.], 2012. Disponível em: 〈http://www.webshoppers.com.br/>. Acesso em: 11 mai. 2012.

FERREIRA, Johnny Herberthy Martins et al. Um Estudo Bibliométrico da Produção Científica em Administração Sobre Alinhamento Estratégico e Tecnologia da Informação. In: XIV

SEMEAD - SEMINÁRIOS EM ADMINISTRAÇÃ̃. São Paulo: [s.n.], 2011. Anais. São Paulo, USP, 2011.

FIALHO, Camila Borges; SANTOS, Letícia Gomes; LÖBLER, Mauri Leodir. O papel das Tecnologia da Informação no ajuste estratégico organizacional: um estado-da-arte sobre alinhamento entre estratégia e planejamento de TI nos anais do EnADI e EnANPAD. In: XIV SEMEAD -

Seminários em Administração. São Paulo: [s.n.], 2011.

FLEURY, Afonso; FLEURY, Maria Teresa Leme. Estratégias empresariais e formação de competências: um quebra-cabeça caleidoscópico da indústria brasileira. 3.ed. 4. reimp. São Paulo: Atlas, 2008.

FREITAS, Henrique et al. O método da pesquisa survey. Revista de Administração, São Paulo, v. 35, n. 3, julho/setembro 2000. p. 105-112.

GHEMAWAT, Pankaj. A estratégia e o cenário dos negócios. 3. ed. Porto Alegre: Bookman, 2012. 
GOLD, Stefan.; HAHN, Rüdiger; SEURING, Stefan. Sustainable supply chain management in "“Base of the Pyramid"" food projects - A path to triple bottom line approaches for multinationals? International Business Review, v. 22, p. 784-799, 2013

HENDERSON, John C.; VENKATRAMAN, N. Venkat. Strategic Alignment: Leveraging information technology for transforming organizations. IBM Systems Journal, v. 38, n. 2 e 3, 1999.

IBGE. @Cidades. IBGE @Cidades, 2010. Disponivel em:

<http://www.ibge.gov.br/cidadesat/xtras/uf.php?coduf=26>. Acesso em: 13 mar. 2013.

LAUDON, Kenneth C.; LAUDON, Jane P. Sistemas de informação gerenciais: administrando a empresa digital. 5. ed. São Paulo: Pearson Prentice Hall, 2004.

LUFTMAN, Jerry. Assessing business-IT alignment maturity. Communications of AIS, v. 4, December 2000.

MCCORMACK, Kevin P.; JOHNSON, William C.; WALKER, William T. Supply chain networks and business process orientation: advanced strategies and best pratices. Boca Raton: CRC Press LLC, 2003.

MARCONI, Marina de Andrade; LAKATOS, Eva Maria. Técnicas de pesquisa: planejamento e execução de pesquisas, amostragens e técnicas de pesquisa, elaboração, análise e interpretação de dados. 7. ed. São Paulo: Atlas, 2009.

MARTINS, Ivan. O paradoxo da produtividade: Onde foi parar todo o dinheiro gasto com computadores? Exame, dez. 1996. Disponível em: <http://exame.abril.com.br/revistaexame/edicoes/0625/noticias/o-paradoxo-da-produtividade-m0053991>. Acesso em: 07 mar. 2013.

MINTZBERG, Henry; AHLSTRAND, Bruce; LAMPEL, Joseph. Safári de estratégia: um roteiro pela selava do planejamento estratégico. 2. ed. Porto Alegre: Bookman, 2010.

O’BRIEN, James A. Sistemas de informação: e as decisões gerenciais na era da Internet. São Paulo: Saraiva, 2001.

O'BRIEN, James A. Sistemas de informação e as decisões gerenciais na era da Internet. 2. ed. São Paulo: Saraiva, 2004.

OLIVEIRA, Djalma de pinho Rebouças de. Planejamento estratégico: conceitos, metodologia e práticas. 22. ed. São Paulo: Atlas, 2005.

PESTANA, Maria Helena; GAGEIRO, João Nunes. Análise de dados para ciências sociais - a complementaridade do SPSS. 4. ed. Lisboa: Edições Lisboa, 2005.

PINTO, Álvaro Vieira. O conceito de tecnologia. Rio de Janeiro: Contraponto, v. 1., 2005.

PORTER, Michael E. Estratégia competitiva: técnicas para análise de indústrias e da concorrência. 16. ed. Rio de Janeiro: Campus, 1996.

PORTER, Michael E. What is Strategy? Harvard Business Review, v. 74, n. 6, Nov./Dec. 1996. 21 p.

PORTER, Michael E. Como as forças competitivas moldam a estratégia. In: PORTER, Michael E. Competição = On competition: estratégias competitivas essenciais. Rio de Janeiro: Campus, 1999 . Cap. 1, p. 28-45. 
PORTER, Michael E.; MILLAR, Victor E. Como a informação proporciona vantagem competitiva. In: PORTER, Michael E. Competição = On competition: estratégias competitivas essenciais. Rio de Janeiro: Campus, 1999. Cap. 3, p. 83-106.

REZENDE, Denis Alcides. Tecnologia da Informação integrada à inteligência empresarial: alinhamento estratégico e análise da prática nas organizações. São Paulo: Atlas, 2002.

REZENDE, Denis Alcides; ABREU, Aline França de. Tecnologia da informação aplicada a sistemas de informações empresariais: o papel estratégico da informação e dos sistemas de informação nas empresas. 7. ed. São Paulo: Atlas, 2010.

RICHARDSON, Roberto Jarry. Pesquisa social: métodos e técnicas. 3. ed. São Paulo: Atlas, 1999.

ROACH, Stephen. White collar productivity: a glimmer of hope? Special Economic Study, 16 September 1988.

ROESCH, Sylvia Maria Azevedo. Projetos de Estágio e de pesquisa em Administração: guia para estágios, trabalhos de conclusão, dissertação e estudos de caso. São Paulo: Atlas, 2005.

SANTOS, Fabiano França; CHAMON, Marco Antonio. A tecnologia da informação e o paradoxo da produtividade. Revista Ciências Exatas, Taubaté, v. 14, n. 1, 2008.

SEBRAE; DIEESE. Anuário do Trabalho na Micro e Pequena Empresa 2009. 3. ed. Brasília; São Paulo: SEBRAE; DIEESE, 2010. Disponivel em: <http://www.sebrae.com.br/customizado/estudos-epesquisas/temas-estrategicos/emprego/anuario_trabalho_2009.pdf >. Acesso em: 06 maio 2012.

SILVA, Andrea Lago da; BATALHA, Mário Otávio. Marketing estratégico aplicado ao agronegócio. In: BATALHA, Mário Otávio (Org.). Gestão agroindustrial: GEPAI : Grupo de Estudos e Pesquisas Agroindustriais. 3. ed. São Paulo: Atlas, v. 1, 2010.

SILVA, Maria da Conceição Melo. Perspectivas do alinhamento estratégico entre negócios e tecnologia da informação em empresas de software do Porto Digital: um prisma de divergentes facetas. Recife: O Autor, 2009. 243 p. Tese (Doutorado) - Universidade Federal de Pernambuco. CCSA, Administração, 2009.

SOLOW, Robert Merton. We'd better watch out. The New York Times Book Review, p. 36, December 1987.

TEIXEIRA FILHO, José Gilson de Almeida. MMPE-SI/TI (Gov) - Modelo de maturidade para planejamento estratégico de SI/TI direcionado às organizações governamentais brasileiras baseado em melhores práticas. Recife: O Autor, 2010. Tese (Doutorado em Ciência da Computação), CIn - Universidade Federal de Pernambuco, Recife, 2010.

TURBAN, Efrain; RAINER, Rex Kelly; POTTER, Richard E. Administração de tecnologia de informação: teoria e prática. Rio de Janeiro: Elsevier, 2005.

VARGAS, Katiuscia de Fátima Schiemer; MOURA, Gilnei Luiz de; BUENO, Daiane de Fátima dos Santos; PAIM, Eliane Suely Everling. A cadeia de valores e as cinco forças competitivas como metodologia de planejamento estratégico. Revista Brasileira de Estratégia-REBRAE, v. 6, n. 1, p. 11-22, 2013.

VERGARA, Sylvia Constant. Projetos e relatórios de pesquisa em administração. 4. ed. São Paulo: Atlas, 2003. 
WAINER, Jacques. O Paradoxo da Produtividade. In: RUBEN, Guilhermo Raúl; WAINER, Jacques; DWYER, Tom (Orgs.). Informática, organizações e sociedade no Brasil. São Paulo: Cortez, 2003. p. 13-55. 